\title{
Right Anterior Cerebellum BOLD Responses Reflect Age Related Changes in Simon Task Sequential Effects
}

Aisenberg, D.; Sapir, Ayelet; Close, Alexander; Henik, A.; D-Avossa, Giovanni

\section{Neuropsychologia}

DOI:

10.1016/j.neuropsychologia.2017.12.012

Published: 31/01/2018

Peer reviewed version

Cyswllt i'r cyhoeddiad / Link to publication

Dyfyniad o'r fersiwn a gyhoeddwyd / Citation for published version (APA):

Aisenberg, D., Sapir, A., Close, A., Henik, A., \& D-Avossa, G. (2018). Right Anterior Cerebellum BOLD Responses Reflect Age Related Changes in Simon Task Sequential Effects.

Neuropsychologia, 109(January), 155-164.

https://doi.org/10.1016/j.neuropsychologia.2017.12.012

\footnotetext{
Hawliau Cyffredinol / General rights

Copyright and moral rights for the publications made accessible in the public portal are retained by the authors and/or other copyright owners and it is a condition of accessing publications that users recognise and abide by the legal requirements associated with these rights.

- Users may download and print one copy of any publication from the public portal for the purpose of private study or research.

- You may not further distribute the material or use it for any profit-making activity or commercial gain

- You may freely distribute the URL identifying the publication in the public portal ?
}

Take down policy

If you believe that this document breaches copyright please contact us providing details, and we will remove access to the work immediately and investigate your claim. 
Right Anterior Cerebellum BOLD Responses Reflect Age Related Changes in Simon Task Sequential Effects

Aisenberg, D. a ${ }^{1}$, Sapir, A. b, Close A. b, Henik, A.a, and d'Avossa, G.b

${ }_{\mathrm{a}}$ Department of Psychology and Zlotowski Center for Neuroscience, Ben-Gurion University of the Negev, Beer Sheva, Israel

bSchool of Psychology and Wolfson Center of Clinical and Cognitive Neuroscience, Bangor University, Wales

${ }^{1}$ Present address: Department of Clinical Psychology - Gerontology, Ruppin Academic Center, Emek Hefer, Israel

Correspondence concerning this article should be addressed to Daniela Aisenberg, Department of Clinical Psychology - Gerontology, Ruppin Academic Center, Emek Hefer, Israel 4025000. Tel: 972-9-8981375. E-mail: danielaa@ ruppin.ac.il

Word count: 6,165 
Highlights:

- In an fMRI study, we examined the BOLD correlates of age-related changes in a Simon task.

- Behaviorally, sequential effects were diminished in old compared to young adults.

- BOLD responses in right anterior cerebellum showed sequential effects in young, but not old adults.

- Aging may interfere with the trial-by-trial updating of stimulus-response mapping. 


\begin{abstract}
Participants are slower to report a feature, such as color, when the target appears on the side opposite the instructed response, than when the target appears on the same side. This finding suggests that target location, even when task-irrelevant, interferes with response selection. This effect is magnified in older adults. Lengthening the inter-trial interval, however, suffices to normalize the congruency effect in older adults, by re-establishing young-like sequential effects (Aisenberg, Sapir, d'Avossa, Henik, 2014). We examined the neurological correlates of age related changes by comparing BOLD signals in young and old participants performing a visual version of the Simon task. Participants reported the color of a peripheral target, by a left or righthand keypress. Generally, BOLD responses were greater following incongruent than congruent targets. Also, they were delayed and of smaller amplitude in old than young participants. BOLD responses in visual and motor regions were also affected by the congruency of the previous target, suggesting that sequential effects may reflect remapping of stimulus location onto the hand used to make a response. Crucially, young participants showed larger BOLD responses in right anterior cerebellum to incongruent targets, when the previous target was congruent, but smaller BOLD responses to incongruent targets when the previous target was incongruent. Old participants, however, showed larger BOLD responses to congruent than incongruent targets, irrespective of the previous target congruency. We conclude that aging may interfere with the trial by trial updating of the mapping between the task irrelevant target location and response, which takes place during the inter-trial interval in the cerebellum and underlays sequential effects in a Simon task.
\end{abstract}

Keywords: Aging, Simon task, Stimulus-response remapping, cerebellum, sequential effects 


\section{Introduction:}

Aging is accompanied by widespread changes in psychomotor and cognitive performance (Craik \& Salthouse, 2011). These changes are characterized, for example, by diminished ability to maintain information in working memory (e.g., Craik et al., 1990; Daigneault \& Braun, 1993; Salthouse, 1990), greater interference by task irrelevant distractors (e.g., Duchek et al., 1998) and diminished ability to withhold automatic, but incorrect responses (e.g., Spieler et al., 1996; West \& Bell, 1997; Zacks et al., 1996). These deficits are thought to interfere with older adults' ability to carry out complex activities (Salthouse, 2016).

\subsection{The Simon task}

The Simon task is a simple experimental paradigm that has been used to examine control processes under speeded conditions. In its visual version (Simon \& Small, 1969), participants are shown a colored target, either on the left or the right of fixation and report its color by pressing either a left or a right key, as soon as the target appears (Craft \& Simon, 1970; Proctor \& Lu, 1994; Umilta \& Nicoletti, 1985). This paradigm yields two basic trial types: congruent trials, when the target is presented on the same side as the key-press instructed by its color; and incongruent trials, when the target is presented on the opposite side. This distinction is crucial since participants are slower to respond to incongruent than congruent targets, suggesting that the location of the target, although task-irrelevant, automatically biases response related processes. The reaction time (RT) difference between incongruent and congruent trials is termed the Simon or congruency effect.

Several explanations for the Simon effect have been offered. The initial interpretation of this effect was that the irrelevant target location is processed automatically and produces response interference (Simon \& Small, 1969). Similarly, Hommel, Müsseler, Aschersleben, and Prinz (2001), suggested that action and perception are encoded by overlapping neural populations. The Simon effect emerges when an irrelevant property of the stimulus (i.e., location) is processed and unavoidably activates the overlapping response representations (i.e., action toward the irrelevant location). Nicoletti and Umiltà (1989) suggested that attention is shifted toward the stimulus and automatically generates a spatial code, which biases the motor response. Van der Lubbe, Abrahams and De Kleine (2012) provided ERP data supportive of the idea that facilitation of actions ipsilateral to the target occurs because spatial orienting and response preparation overlap. While it is still under debate which reference frame 
is used to code the stimulus location (Abrahamse \& Van der Lubbe, 2008; Van der Lubbe \& Abrahamse, 2011; Van der Lubbe, et al., 2012; Hommel, 2011), it is agreed that the Simon effect reflects the interference of task irrelevant Stimulus-Response (S-R) association.

The existence of sequential effects has further informed the debate about the nature of the Simon effect. Responses to congruent and incongruent trials depend on the congruency of the target in the previous trial, so that responses to congruent targets are slower when the previous trial contained an incongruent than a congruent target. Likewise, responses in incongruent trials are faster when the previous trial contained an incongruent than congruent target (Gratton, Coles, \& Donchin, 1992). These sequential effects result in a smaller Simon effect when the preceding trial contains an incongruent target. Two main explanations have been suggested to account for this finding (Egner, 2007; Duthoo, Abrahamse, Braem, Boehler, \& Notebaert, 2014); Sequential effects may reflect a conflict monitoring process. That is, the detection of conflict in incongruent trials leads to recruitment of processes which inhibit the processing of the task irrelevant spatial dimension. When the next target is presented, these inhibitory processes diminish the interference of the target location and, consequently, the size of the Simon effect (Botvinick, Braver, Barch, Carter \& Cohen, 2001). Alternatively, sequential effects may reflect trial by trial binding of target features and response. That is, for a response to be executed, target features and response need to be jointly encoded. These bound representations are generated rapidly if the target features are fully repeated, e.g., a trial containing a blue target on the left is followed by a trial containing a blue target on the left, or completely changed, e.g., when a blue target on the left is followed by a red target on the right. However, if the target features are partially repeated, the representation of the previous trial must first be unbound before the representation of the current trial is coded, resulting in a slowed response. As full repetition and complete changes correspond to sequences of either congruent-congruent or incongruent-incongruent targets, while partial repetitions correspond to sequences of congruent-incongruent or incongruent-congruent targets, this proposal provides a potential explanation for these sequential effects (Hommel, Proctor \& Vu, 2004; Mayr, Awh \& Laurey, 2003).

\subsection{The Simon task and Aging}

Several studies tested Simon task in older participants and found a larger Simon effect (Van Der Lubbe \& Verleger, 2002; Bialystok, Craik, Klein \& Viswanathan, 2004; 
Aisenberg et al., 2015). This age effect is mostly driven by older adults showing a disproportionate slowing when responding to incongruent targets (Aisenberg, Sapir, d'Avossa \& Henik, 2014; Aisenberg et al., 2015). One possible interpretation of this finding is that inhibitory processes are impaired in aging, and therefore, the ability to suppress the irrelevant target location is diminished (Aisenberg et al., 2015).

However, Aisenberg et al., (2014) found that older adults not only suffer a larger Simon effect, but also diminished sequential effects, suggesting that the former is a consequence of the latter. While the loss of sequential effects in older adults may still be accounted in terms of an inhibitory deficit, other aspects of Aisenberg's findings are not fully consistent with this specific hypothesis. In particular, young adults showed a pattern of reversed Simon effect on trials preceded by an incongruent target. In other words, young adults were faster to respond to incongruent than congruent targets when the preceding target was incongruent. While the reversed congruency effect was not significant, it was consistently found across experiments, and replicated reports from other labs (e.g., Hommel, 1993; Stürmer, Leuthold, Soetens, Schröter \& Sommer, 2002). This reversal cannot be explained if sequential effects only reflect inhibition of the task irrelevant spatial dimension.

Remarkably, these age-related performance differences could be diminished simply by increasing the duration of the inter-trial interval (ITI). While older adults showed loss of sequential effects when the ITIs were short, sequential effects were reestablished when ITIs were long. The ITIs duration did not affect sequential effects in young participants. This indicates that aging effects on the Simon task reflect the slowing of preparatory processes, which take place during the ITI. The observation that these processes take place after the trial had ended suggests that they reflect a proactive mode of control (Braver 2012). This finding cannot be easily explained by the theoretical accounts of the sequential effects in the Simon task offered by Hommel $(2004 ; 2011)$ and reviewed in the previous section. According to this model, the costs associated with partial feature repetition are incurred only after the current stimulus is presented, since unbinding the memory representation of the previous trial can only begin then. Therefore, there is no obvious reason why the duration of the ITI should affect the cost of unbinding. One may speculate that aging leads to a faster decay of the previous trial memory trace. However, this hypothesis predicts a loss of sequential effects at long rather than short ITIs. In conclusion, inhibitory processes cannot explain the reversal of the Simon effect following an incongruent trial, while the 
feature binding proposal cannot explain why the duration of the ITI affects sequential effects in older adults.

Aisenberg et al, (2014) proposed, instead, that age related changes in sequential effects may reflect slowed updating of the mapping between stimulus location and response. This mapping provides a general rule to transform target position into a response, for example mapping eccentric targets onto the hand either on the same or the opposite side. This proposal differs from the binding hypothesis, first because it assumes that the brain holds on to rules rather than a representation of the last trial event. Moreover, and unlike the binding hypothesis, which assumes that binding processes must be completed by the time the response is made, the remapping proposal could account for the age related ITI effects if one assumes that remapping takes place after the response and is delayed in older adults.

Imaging studies have been instrumental in identifying the functional anatomy of the processes underpinning performance in the Simon and related tasks. These studies have reported that dorso-lateral prefrontal cortex (DLPFC) and anterior cingulate cortex (ACC) show larger activations to incongruent than congruent targets (Fan, Flombaum, McCandliss, Thomas, \& Posner, 2003; Jonides, Badre, Curtis, ThompsonSchill, \& Smith, 2002; Peterson et al., 2002; Van Der Lubbe \& Verleger, 2002). These findings were interpreted according to the view that these regions belong to a frontal circuit that monitors performance and maintains goal directed behavior. This same circuit appears to be involved in sequential effects (Botvinick, Cohen, Carter. 2004). Specifically, BOLD responses to incongruent targets in ACC are modulated by the previous trial congruency, being larger when the previous trial is congruent than incongruent (Botvinick, Nystrom, Fissell, Carter, Cohen, 1999), suggesting that ACC is specifically tuned to the 'de novo' appearance of incongruent targets. Additionally, trial to trial fluctuations in the amplitude of ACC activation, following an incongruent target, was found to predict the strength of sequential effects in both a Stroop (Kerns, Cohen, Carter, 2004) and a Simon task (Kerns, 2006), suggesting that variations in conflict detection affect the strength of behavioral adjustments made in subsequent trials. Finally, patients undergoing cingulotomies have been found to lose sequential effects, following the surgical procedure, without any detectable change in the size of the congruency effects (Sheth et al., 2012). This suggested role of the ACC provides a speculative explanation for the loss of sequential effects observed in older adults. 
Namely, aging diminishes the ability of ACC to detect conflict following incongruent targets and initiate adjustments in attentional control on subsequent trials. Support for this hypothesis stems largely from the observation that older adults suffer a disproportionate performance decrement, when presented with distractors. According to an anatomically based hypothesis, the increased interference of distractors in aging arises because the ACC, which monitors the internal and external environment and detects sources of conflict that could lead to erroneous responses (Banich et al., 2000; Botvinick et al., 1999; Carter et al., 2000; MacDonald et al., 2000), may be prominently vulnerable to aging. If so, the BOLD response in ACC during a conflict task involving distractors, such as the Simon task, should be diminished in old compared to young participants.

Despite the prevailing view that frontal networks involved in cognitive control are responsible for sequential effects, some studies have implicated sensori-motor networks, in keeping with our suggestion that sequential effects may reflect adjustments in mapping of the target location onto a response. For example, Wittfoth, Buck, Fahle and Herrmann (2006), who used two variations of the Simon task, found greater BOLD responses to incongruent than congruent targets in attentional, motor and visual regions, including the pre-supplementary motor area (pre-SMA), superior parietal lobule (SPL), cuneus, left fusiform gyrus, and cerebellum. Interestingly, the authors did not find consistently BOLD signal changes in either the ACC or the DLPFC and therefore concluded that conflict can be detected and processed in visual and motor networks, tied to the analysis of the stimulus and the generation of the appropriate response. If this is correct, age related changes in the BOLD response should be detected in motor, attentional and visual regions, and in regions involved in stimulus-response remapping.

\subsection{The Current Study}

The present study aims to identify the functional anatomical correlates of the agerelated changes in sequential effects, which should help establish the nature of the processes underling these effects. We reasoned that if age-related changes reflect a deficit in either conflict detection or inhibition, one should expect age related differences in regions such as the PFC, the ACC and anterior Insula (Fan et al., 2003; Jonides et al., 2002; Peterson et al., 2002; Van Der Lubbe \& Verleger, 2002). On the other hand, if age-related changes in sequential effects reflect a failure in promptly updating stimulus response mapping, then age related changes should be found in sensori-motor brain regions, such as the cerebellum, intra-parietal sulcus (IPS) and 
SMA. A number of imaging studies, which provided support for the conflict monitoring hypothesis, specifically examined the effects of the previous target congruency on BOLD responses evoked by incongruent targets (Fan et al., 2003; Jonides et al., 2002; Peterson et al., 2002). The presumptive reason for this analytical strategy is that the conflict monitoring hypothesis predicts that BOLD responses to congruent targets should not be affected by the congruency of the previous target, since no information conflict is present on these trials. On the other hand, the remapping hypothesis suggests that BOLD responses to both congruent and incongruent targets should be modulated by the congruency of the target in the previous trial. Therefore, in our analysis of age related changes in sequential effects, we examined all possible pairings of present and the previous target congruency. Our main aim was to identify brain regions where the BOLD response showed sequential effects in young but not old participants.

Because the shape of the BOLD response differs in young and old participants, we did not use an assumed hemodynamic response function to estimate the BOLD response. Instead, we estimated the BOLD response on a frame by frame basis by jittering the ITI duration. This design assumed that the same processes are recruited during short and long ITIs, in keeping with the finding that when mixing short and long ITIs in the same block, sequential effects are driven by the short ITI (see experiment 2 in Aisenberg et al., 2014). Since the ITI duration in mixed blocks is not expected to modulate sequential effects, the effects of ITI on the BOLD response are not investigated in this study.

2.

Materials and Method

\subsection{Participants.}

Thirteen healthy older adults (mean age $=70.7$ years, $S D=4$ years, range $=65-77$ years) and seven healthy young adults (mean age $=25.5$ years, standard deviation $(S D)=2.5$ years, range $=23-3$ years) were recruited from the School of Psychology community panel at Bangor University in Bangor, UK. All participants gave written informed consent prior to engaging in any experimental procedure. The experimental protocol was approved by the Bangor University School of Psychology Ethics Board. All participants were right handed and were screened for a history of neurological and psychiatric disorders. Older adults were also screened with the Mini-Mental Status Exam (Folstein, Folstein, \& McHugh, 1975), and those who scored less than 27 were 
excluded from further testing. Color vision was assessed in all participants with the Ishihara Color Test. Participants were paid $£ 20$ for their participation.

\section{$\underline{2.2 \text { Behavioral tasks }}$}

The task required participants to report the color of a visual target, by pressing a key, with either the left or the right hand. The targets were either a red or a blue circle, $5^{\circ}$ in diameter, which could be displayed $13^{\circ}$ left, right, above or below the central fixation point. Target color and position varied in a fully factorial design. This yielded two incongruent targets, when the target appeared on the opposite side of the keypress instructed by its color; two congruent targets, when the target and the instructed key-press were on the same side; and two neutral targets, when the target appeared either above or below fixation. Each block contained ninety-one trials, with at least thirty trials of each type (congruent, incongruent and neutral). Moreover, each of the nine possible sequential pairings between target types occurred ten times in a block. The order of the presentation was randomized. Participants completed a practice block of sixteen trials in the scanner, prior to commencing the actual imaging procedure. Each participant completed at least 5 scans. Some participants performed up to additional 3 more scans. Specifically, 6 participants completed 8 blocks (5 young and 1 old), 8 participants completed 7 blocks (1 young and 7 old), 5 old participants completed 6 blocks, and 1 young participant completed 5 blocks.

The duration of the inter-trial interval (ITI) was jittered over three levels: $2.5 \mathrm{~s}$, 5.0s and 7.5s (Buckner, 1998; Dale \& Buckner, 1997). The short, intermediate and long ITIs represented $60 \%, 30 \%$ and $10 \%$ respectively of the total.

Each trial started with a 1.0s long central black fixation cross. This was followed by the target, which remained visible for $400 \mathrm{~ms}$. A grey asterisk followed, which remained visible at the center of the screen during the ITI. In the practice block, whenever the participant made an erroneous response, the word "error" appeared for 1.0s, before the inception of the following trial. No feedback was provided during the imaging procedure.

\subsection{Functional imaging}

The data were acquired on a 3T Philips MRI scanner with a sensitivity-encoded (SENSE) phased-array head coil. For functional imaging, a single shot echo planar imaging sequence was used $(\mathrm{T} 2 *$-weighted, gradient echo sequence; repetition time $(\mathrm{TR})=2,500 \mathrm{~ms} ;$ time to echo $(\mathrm{TE})=35 \mathrm{~ms}$; flip angle $\left.(\mathrm{FA})=90^{\circ}\right)$ to achieve nearly whole cerebrum coverage. The scanning parameters were as follows: $\mathrm{TR}=2,500 \mathrm{~ms}$; 
30 off-axial slices; slice pixel dimensions, $2 \times 2 \mathrm{~mm}^{2}$; slice thickness, $3 \mathrm{~mm}$; no slice gap; field of view (FOV) $224 \times 224 \mathrm{~mm}^{2}$; matrix $112 \times 112$; phase-encoding direction, A-P (anteroposterior); SENSE factor $=2$. Seven dummy volumes were acquired before each functional run to minimize T1 saturation effects. Parameters for T1-weighted anatomical scans were: $288 \times 232$ matrix; $1 \mathrm{~mm}^{3}$ isotropic voxels; $\mathrm{TR}=$ $8.4 \mathrm{~ms} ; \mathrm{TE}=3.8 \mathrm{~ms} ; \mathrm{FA}=8^{\circ}$.

\subsection{Data analysis.}

Sync-interpolation was used to correct for between-slice differences in acquisition time. BOLD signal in each volume was normalized to a modal voxel value of 1,000 to facilitate comparison between datasets (Ojemann et al., 1997). Imaging data were corrected for head motion within and across runs using a rigid-body six degree of freedom affine transformation (Snyder, 1996). Data were resampled into $3 \mathrm{~mm}$ isotropic voxels and transformed to the Talairach and Tournoux (1988) reference space using twelve degrees of freedom.

2.4.1 Event-related design. Data were analysed using a general linear model (GLM) (Friston et al., 1994; Miezin et al., 2000). The model included the following parameters: a constant, a linear term and a set of cosine and sine functions, modelling fluctuations of the BOLD signal with a period less than $0.009 \mathrm{~Hz}$. The model also included a set of parameters of interest, namely seven consecutive delta functions, comprising the interval between 0 and $15 \mathrm{~s}$ after the stimulus onset. The GLMs assessing sequential effects, for example, included 9 sets of regressors, one for each possible combination of previous and present target congruency. Three additional sets of regressors were used to model the BOLD response to the first target in the block and in trials where the behavioral response to the previous or present target was erroneous. The percentage of BOLD signal modulation was calculated as a ratio, whose numerator was the BOLD signal amplitude, and the denominator the value of the constant term, averaged over scans (Ollinger, Corbetta, \& Shulman, 2001). GLM estimates for each participant were smoothed with a $6.0 \mathrm{~mm}$ FWHM Gaussian filter. Group level statistics were based on mixed ANOVAs. The between factor was age and the within factors included present target congruency, previous target congruency and time. The time factor was defined over seven levels, spanning the first 15.0s after the target onset. Regions of interest (ROIs) were derived from voxel-wise, group level z-transformed statistical maps, corrected for multiple comparisons using joint zscore/cluster size thresholds (Forman, Cohen, Fitzgerald, Eddy, Mintun \& Noll, 1995). A voxel survived correction if its $\mathrm{z}$ score was greater than 3.0 and belonged to 
a cluster of at least 13 voxels with contiguous edges. The z-score/cluster size thresholds were determined using volume-based Monte Carlo simulations (McAvoy, Ollinger \& Buckner, 2001). Each ROI was centred on a peak activation identified using an automated search algorithm (Mintun, Fox \& Raichle, 1989) and was drawn by hand to ensure that voxels belonging to separate but adjoining structures were assigned to the correct ROI.

\section{Results}

\section{$\underline{3.1 \text { Behavioral results }}$}

Overall, the error rate was low (3\% for young adults and 5.5\% for old adults) and did not differ between age groups, $F(1,18)<1$. Mean RTs were calculated for correct response only and for each participant and condition. Post error trials were removed from the analysis. Outlier responses (i.e., responses that were shorter than $150 \mathrm{~ms}$ or were three standard deviations above/below the mean of each participant within each condition) were excluded from the analysis. This procedure removed an additional $2.6 \%$ of the trials. All main effects were significant (see Table 1, which lists all the significant main effects and interactions) The interaction of the previous by present trial congruency was significant, indicating that the magnitude of the Simon effect in the present trial was affected by the congruency of the target in the previous trial. The age by present trial congruency interaction was significant, due to a larger congruency effect in old than young adults. The three-way interaction between age, previous trial congruency and present trial congruency was also significant, (see Figure 1). Specifically, pattern of sequential dependencies differed in the two groups: young participants showed a significant sequential effect, as indicated by the present $\mathrm{x}$ previous congruency interaction $(\mathrm{F}(1,18)=6.42, \quad \mathrm{MSE}=858.5, \mathrm{p}<.0023)$. This interaction was not significant for old adults $(\mathrm{F}<1)$. Additionally, the Simon effect was only significant in young adults when the previous trial was congruent $(\mathrm{F}(1,18)=39.46, \mathrm{p}<.000005, \mathrm{MSE}=570)$, but not when it was incongruent $(\mathrm{F}(1,18)$ $<1)$. In older adults the Simon effect was significant when the previous trial was either congruent $(\mathrm{F}(1,18)=27.86 \mathrm{p}<.000061, \mathrm{MSE}=570)$ or incongruent $(\mathrm{F}(1,18)=6.722$, $\mathrm{p}<.018, \mathrm{MSE}=252$ ). The results indicate that older adults are less likely to adjust performance based on the previous target congruency.

In order to confirm that mixing short with long ITIs produced the same sequential effects, we compared RTs following short (2.5s) and long (5.0 and 7.5s) ITIs. We found that old adults do not gain sequential effects following long ITIs (ITI x previous 
$\mathrm{x}$ present congruency in old participants $\mathrm{F}<1$ ), suggesting that sequential effects in the scanner were determined by the shortest ITI in the block, in agreement with our previous behavioural findings (Aisenberg et al. 2014).

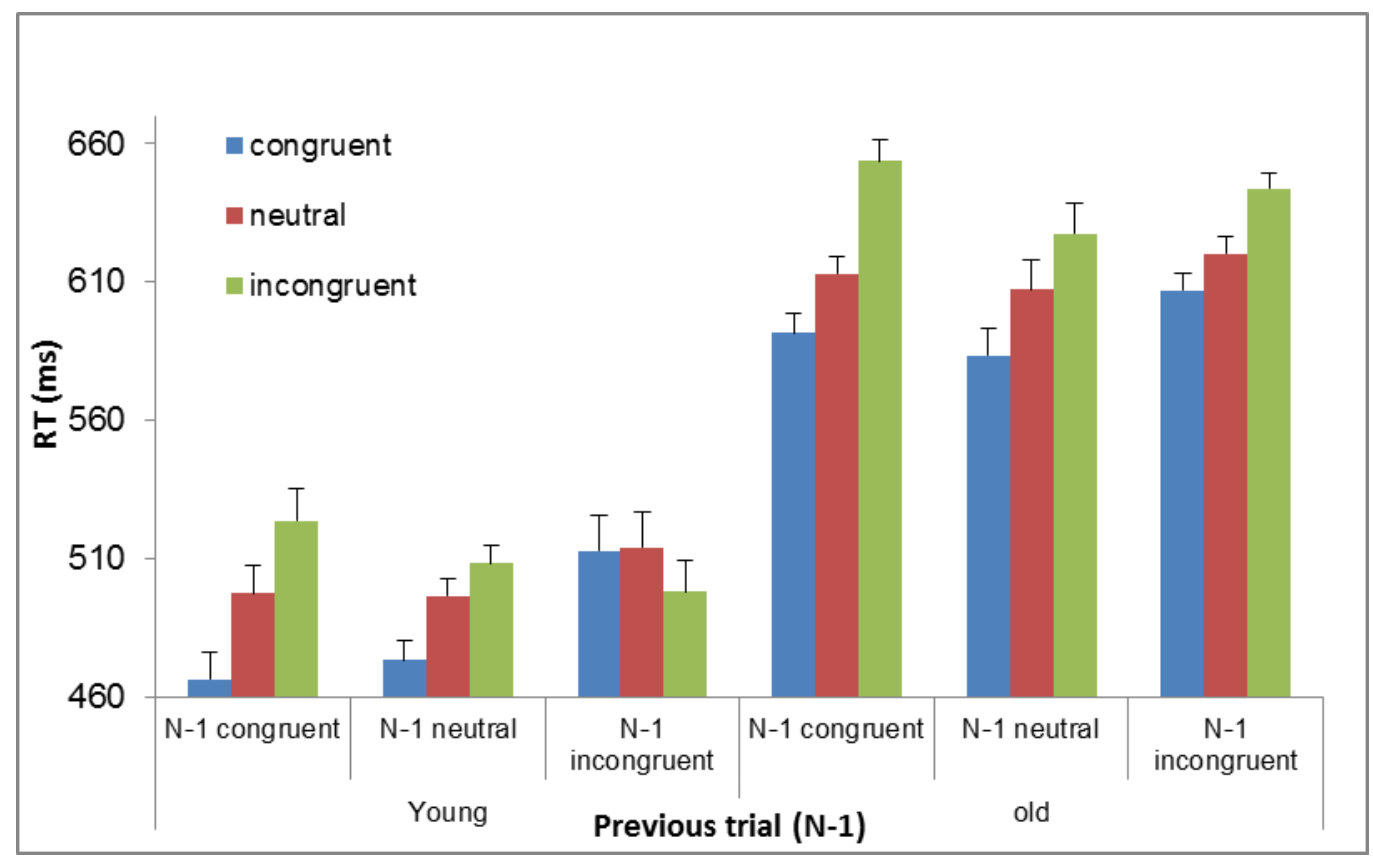

Figure 1. Group averaged RTs. The graph shows RTs in young and old participants sorted by the target's congruency in previous and present trials. The error bars are standard errors of the mean.

\begin{tabular}{lcccccc}
\cline { 2 - 6 } \multicolumn{1}{c}{ Effect } & \multicolumn{1}{c}{ Comments } & $d f$ & $\boldsymbol{F}$ & $\boldsymbol{M S E}$ & $\eta_{2} \mathrm{p}_{\mathrm{p}}$ & $\boldsymbol{p}<$ \\
\hline Age & young are faster than seniors & 1,18 & 6.87 & 60,746 & .27 & .017 \\
present trial congruency & & 2,36 & 49.46 & 371 & .73 & .000 \\
previous trial congruency & & 2,36 & 14.07 & 459 & .43 & .000 \\
previous X present congruency & & 4,72 & 9.42 & 428 & .34 & .000 \\
age X previous trial congruency & & 2,36 & 1.1 & 428 & .03 & $n . s$ \\
age X present trial congruency & & 2,36 & 3.56 & 371 & .16 & .038 \\
interference: young vs. seniors & young - 13 ms, seniors - 23 ms & 1,18 & 5.23 & 381 & & .03 \\
proportional interference: young vs. & young - 47\%, seniors - 69\% & 1,18 & 4.57 & .165 & .2 & .046 \\
seniors & & & & & & \\
age X previous congruency X present & & 4,72 & 3.12 & 428 & .14 & .01 \\
congruency & & & & & & \\
sequential Gratton: young vs. seniors & young - yes, seniors - no & 1,18 & 5.53 & 858.5 & & 0.03
\end{tabular}


Table 1. Main Effects, Interactions and Relevant Contrasts of the Behavioral Results

\subsection{Imaging results.}

Age $\mathrm{X}$ Time interaction: target evoked BOLD responses showed a time by age interaction in several regions, listed in Table S1 in the supplementary materials. This interaction reflected a difference in both the amplitude and the latency of target evoked BOLD responses between old and young adults. Figure 2 shows five representative regions chosen from the age by time interaction map. These regions show target evoked BOLD response whose time-courses differed significantly between young and old participants. In the left and right Para Hippocampal Gyrus (PHG) BOLD responses evoked by targets presented on the left vs. right side had similar amplitudes (both $\mathrm{F}<1$ ), in keeping with these regions weak retinotopic organization (Arcaro, McMains, Singer \& Kastner, 2009). The left PHG showed a significant effect of target congruency $(F(6,108)=2.26, p<0.01)$, but not so the right PHG $(\mathrm{F}(6,108)=1.42, \mathrm{p}=0.15)$. The other three regions shown in figure 2 are right Supplementary Motor Area (SMA), left ACC and right anterior Insula. In right SMA and ACC, neither the current target congruency by time, nor the current target congruency by age by time interaction was significant at the regional level, even though both these regions showed greater BOLD response to incongruent than congruent targets (all $\mathrm{F}<1$ ). Right anterior Insula, on the other hand did show a significant interaction of target congruency by age by time at the regional level $(\mathrm{F}(6.102)=2.24, \mathrm{p}<0.012)$. More generally, figure 2 clearly demonstrates that BOLD responses peaked approximately 5.0s after the target onset in young participants, while in older participants the BOLD response peaked later and appeared more sustained. Also, BOLD responses were of smaller amplitude in old than young participants. These findings are in keeping with previous observations in old adults (Buckner, Snyder, Sanders, Raichle, \& Morris, 2000; D’Esposito et al., 1999; Huettel, Singerman, \& McCarthy, 2001).

Age $\mathrm{X}$ present target congruency $\mathrm{X}$ time interaction: The congruency by age by time interaction highlighted regions listed in Table 2 . In these regions, target congruency modulated the time-course of the BOLD response differently in old and young participants. Figure 3 shows four representative regions. We did not include the left Fusiform Gyrus and Inferior Temporal Gyrus regions, which were not covered in some participants because of their very ventral position. In task positive regions, such as left Superior Parietal Lobule (SPL), right Fusiform Gyrus (FG) and left medial 
Motor Cortex, greater BOLD responses followed incongruent than congruent targets in both young and old adults early after target onset (see figure 3). In right RetroSplenial Cortex (RSC), greater deactivations were however found in young than old participants. Moreover, left medial Motor Cortex, right RSC and left FG all showed age and target congruency effects on deactivations taking place at later timepoints in the response. We computed regional level ANOVAs where the time factor varied over 4 levels only, which included time frames from $7.5 \mathrm{~s}$ to $15.0 \mathrm{~s}$ after target onset. This interaction was significant (respectively, $F(6.102)=4.31, p<0.003$; $\mathrm{F}(6.102)=2.63, \mathrm{p}<0.021 ; \mathrm{F}(6.102)=4.63, \mathrm{p}<0.001)$ suggesting that while more negative BOLD responses followed incongruent than congruent targets in young participants, late BOLD response were less modulated by target congruency in old adults (see Figure3).

\begin{tabular}{|c|c|c|c|c|c|}
\hline Brain region/ Coordinates & $\mathrm{X}$ & $\mathrm{Y}$ & $\mathrm{Z}$ & $\mathrm{Z}$ score & Cluster size $\left(\mathrm{mm}^{3}\right)$ \\
\hline L Fusiform Gyrus & -29 & 0 & -45 & 4.82 & 324 \\
\hline R RetroSplenial Cortex & 3 & -53 & 23 & 4.46 & 270 \\
\hline L Superior Parietal Lobule & -8 & -80 & 32 & 4.30 & 432 \\
\hline R Fusiform Gyrus & 47 & -52 & -21 & 3.87 & 270 \\
\hline R Precuneus & 5 & -55 & 37 & 3.81 & 216 \\
\hline L inferior Temporal Gyrus & -43 & 0 & -45 & 3.79 & 270 \\
\hline L Motor Cortex & -3 & -19 & 55 & 3.73 & 216 \\
\hline Posterior Cingulate Cortex & 0 & -46 & 29 & 3.67 & 432 \\
\hline
\end{tabular}

Table 2 - Talairach Coordinates of the Peaks in the present target congruency by age by time multiple comparison corrected z-transformed map 

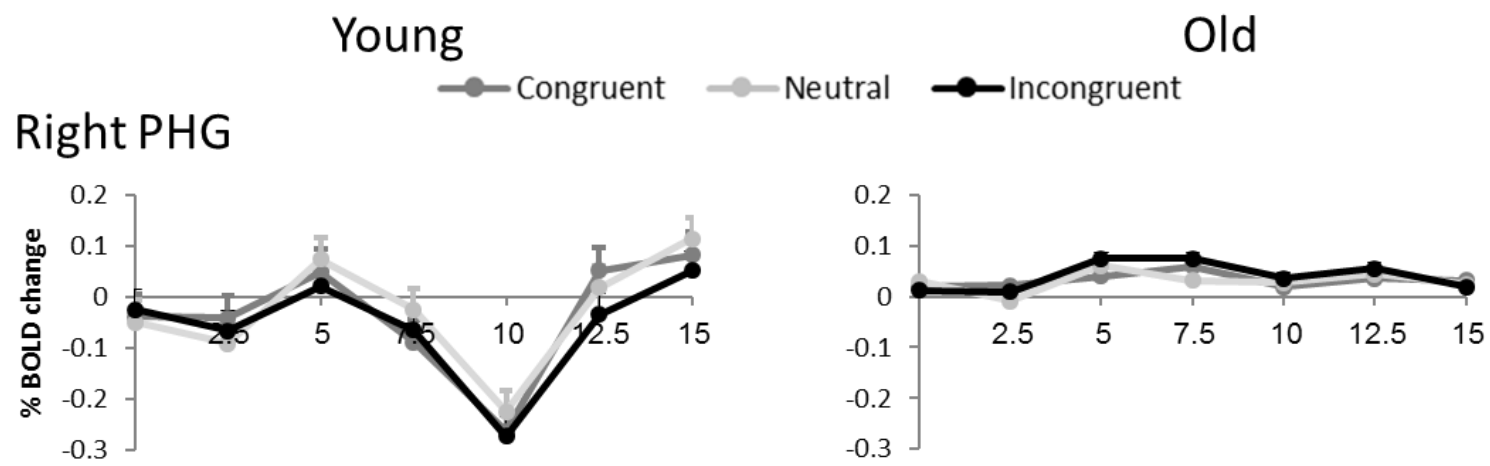

\section{Left PHG}
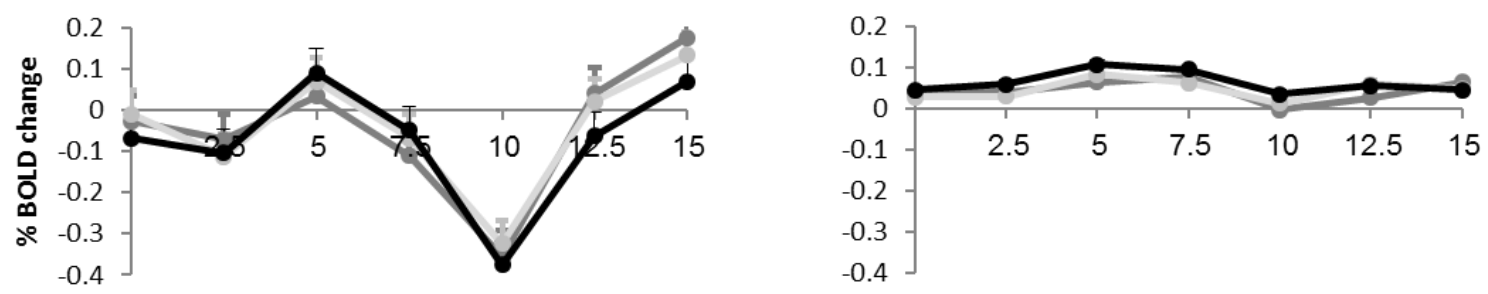

\section{Right SMA}
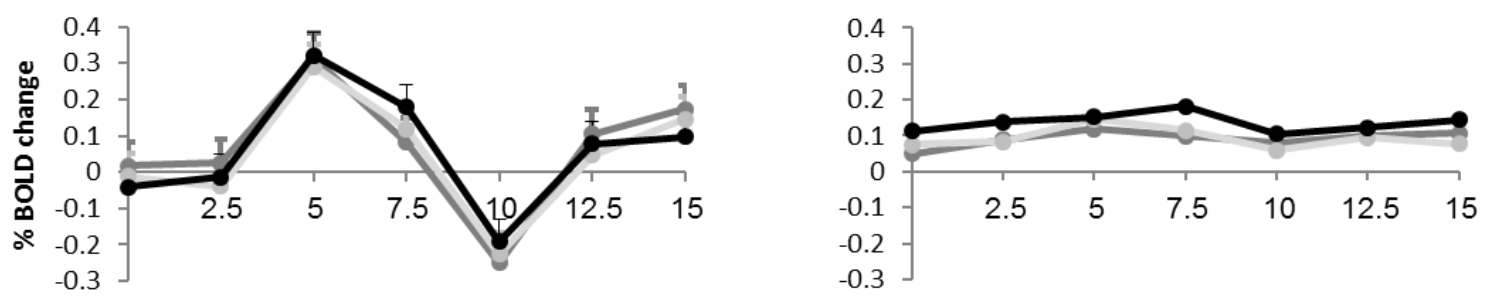

\section{Left ACC}

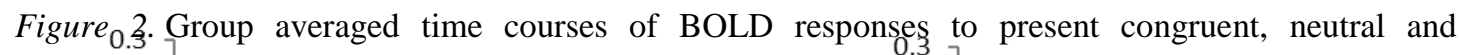
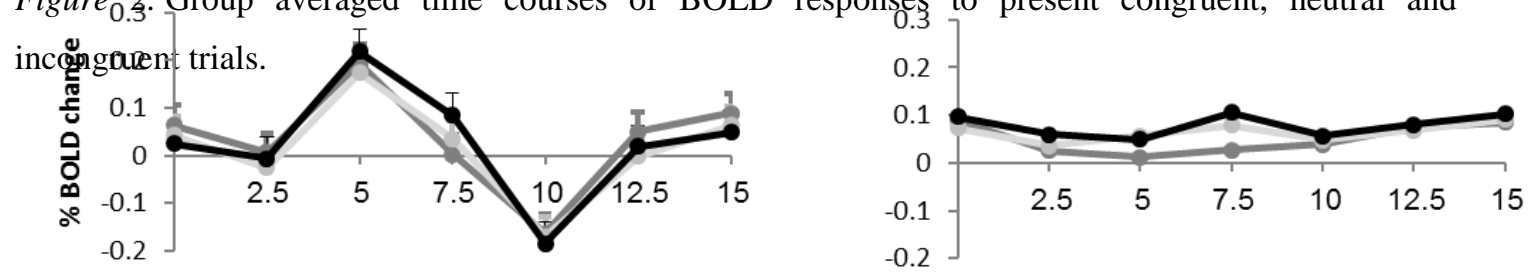

\section{Right Anterior Insula}
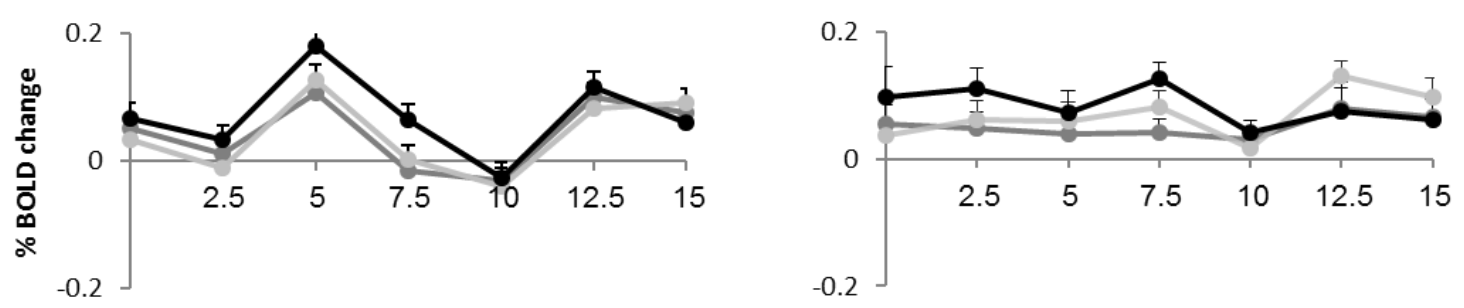

time (s) 


\section{Left SMA}

$\multimap$ Congruent $\multimap$ Neutral $\leadsto$ Incongruent
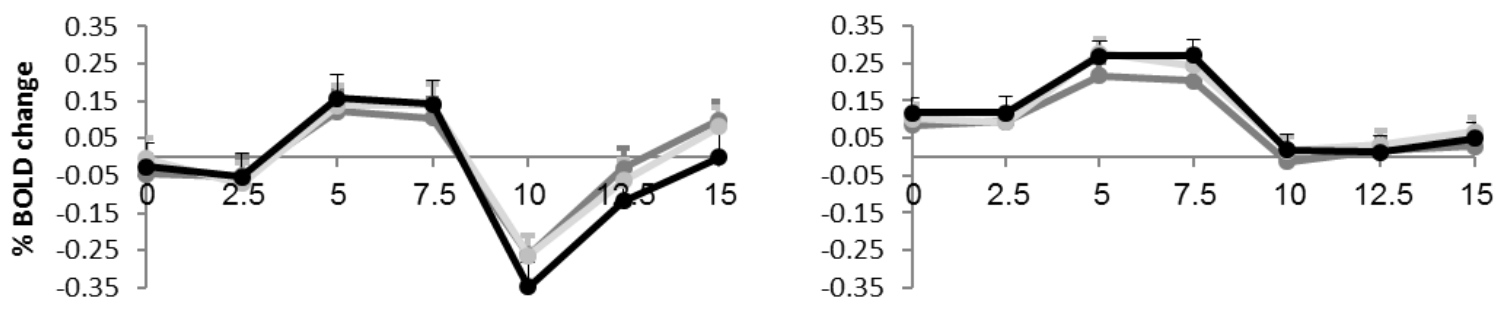

Right RetroSplenial
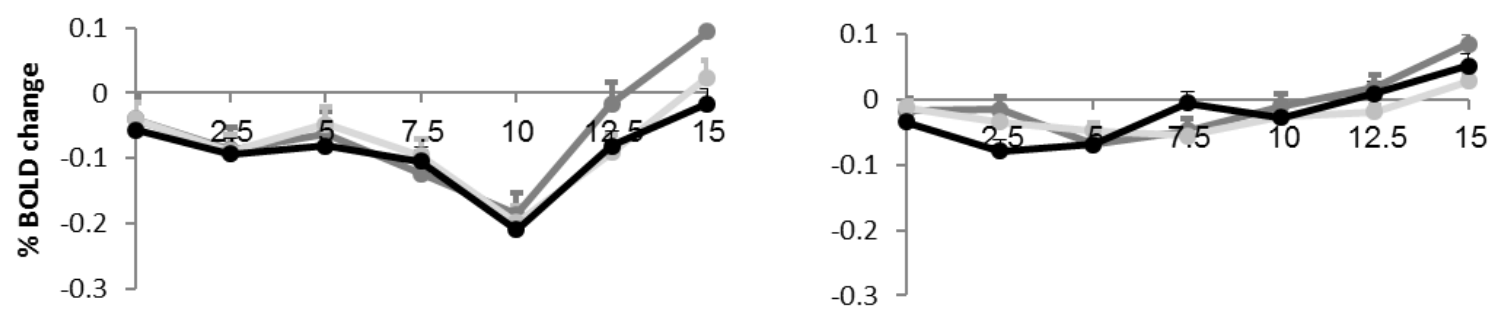

Left SPL
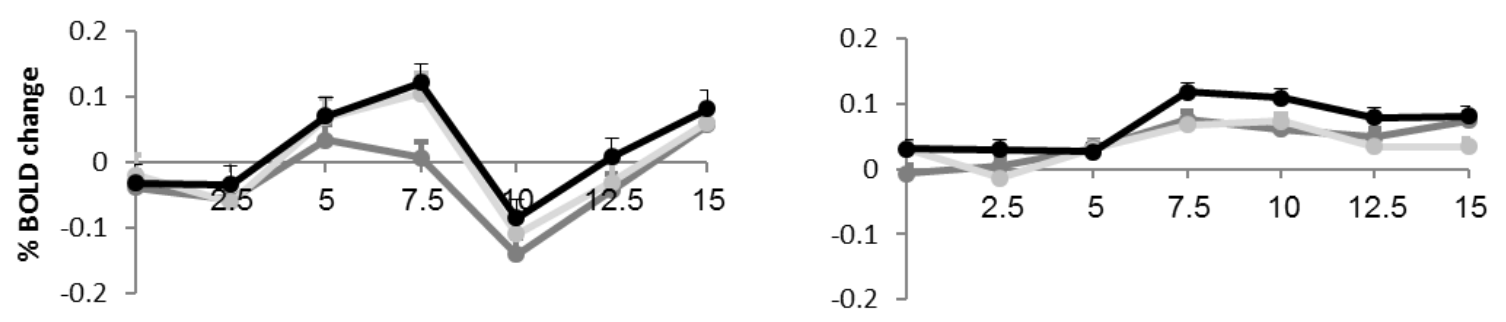

\section{Right Ventral Fusiform}
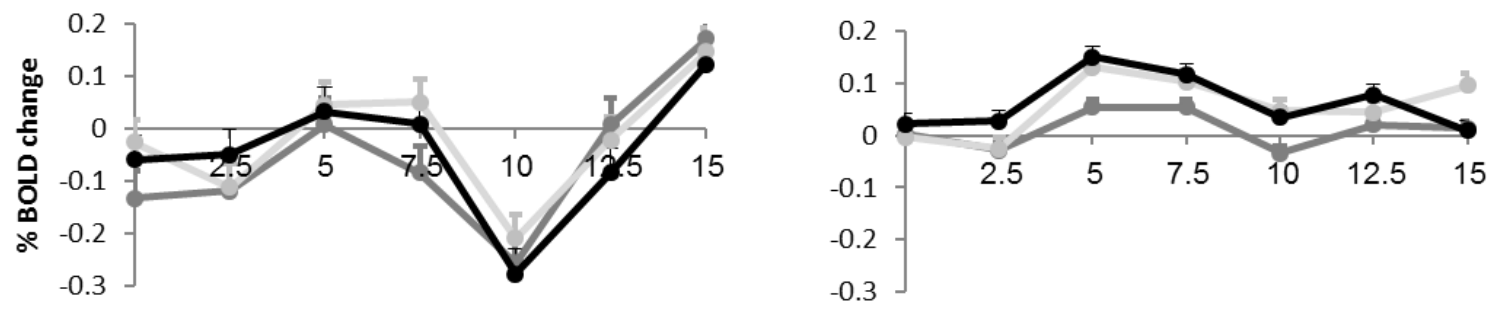

time (s)

Figure 3. Group averaged time courses of BOLD responses to present congruent, neutral and incongruent trials.

In contrast to previous studies (Fan et al., 2003; Peterson et al., 2002), we did not find significant present target congruency effects in either the ACC or the DLPFC, in young and old adults. Namely, the present congruency by time and the present congruency by age by time effects were not significant at the regional level [all $\left.F_{s}<1\right]$. Nevertheless, while the effects of target congruency on BOLD signals in ACC were small and not significant, we did find congruency effects in the anterior Insula, which commonly co-activates with the ACC (Dosenbach et al., 2006), and belongs to 
the same resting state network (Dosenbach et al., 2007; Seeley et al., 2007). This finding suggests that general control processes may have been affected by present target congruency.

Present $X$ previous trial congruency $X$ time interaction: Next, we identified regions where the sequential effects affected the BOLD response. These regions were obtained from the present trial by previous trial congruency by time interaction image. Sequential effects were observed in the visuo-motor network (see table 3).

Present $\mathrm{X}$ previous trial congruency $\mathrm{X}$ age $\mathrm{X}$ time interaction: The only region showing a significant interaction with age was the right anterior cerebellum: young adults showed greater activation on congruent than incongruent trials when the previous trial was incongruent. Vice-versa, the same region showed greater activation on incongruent than congruent when the previous trial was congruent. Old adults, however, did not show this sequential effect. In old adults, incongruent trials evoked greater activation regardless of the congruency of the previous trial (see Figure 4).

\begin{tabular}{|c|c|c|c|c|c|}
\hline Brain region/ Coordinates & $\mathrm{X}$ & $\mathrm{Y}$ & $\mathrm{Z}$ & $\mathrm{Z}$ score & Cluster size $\left(\mathrm{mm}^{3}\right)$ \\
\hline L PostCentral Gyrus & -41 & -26 & 58 & 5.46 & 270 \\
\hline L PostCentral Gyrus & -42 & -28 & 46 & 4.65 & 324 \\
\hline R Cerebellum & 22 & -56 & -21 & 4.27 & 729 \\
\hline R Cerebellum & 15 & -61 & -18 & 4.07 & 432 \\
\hline L Central Sulcus & 36 & -24 & 50 & 3.67 & 324 \\
\hline L Striate Cortex & -14 & -75 & -1 & 3.35 & 432 \\
\hline L PreCentral Gyrus & -39 & -15 & 59 & 3.10 & 432 \\
\hline
\end{tabular}

Table 3 - Talairach Coordinates of the Peaks in the previous target congruency by present target congruency by time multiple comparison corrected z-transformed map 


\section{Young}

Previous congruent

$\rightarrow$ current_congruent $\rightarrow$ current_incongruent

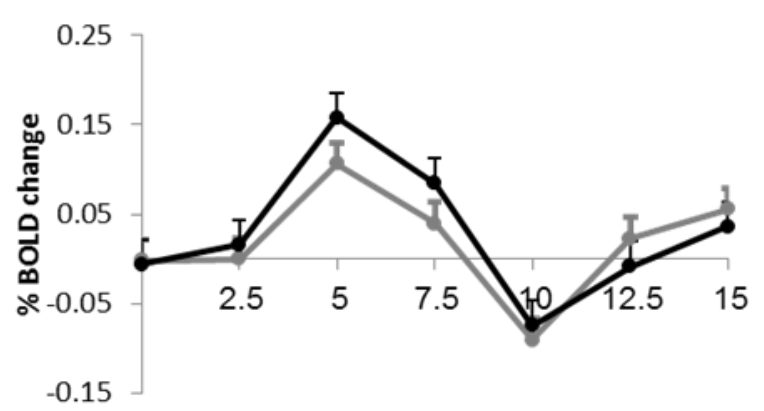

Previous incongruent

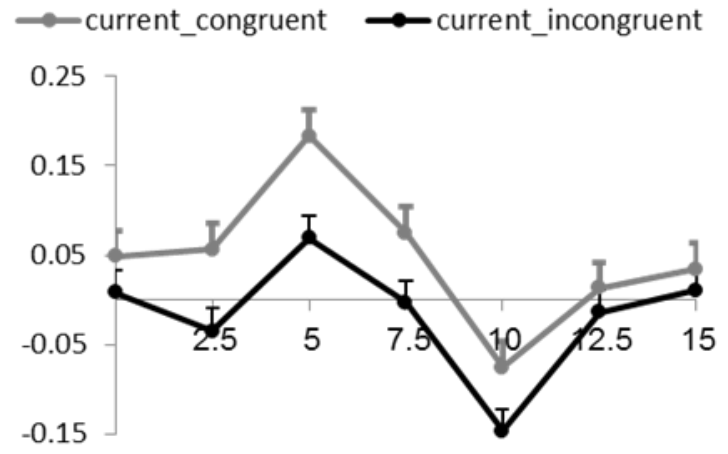

Old
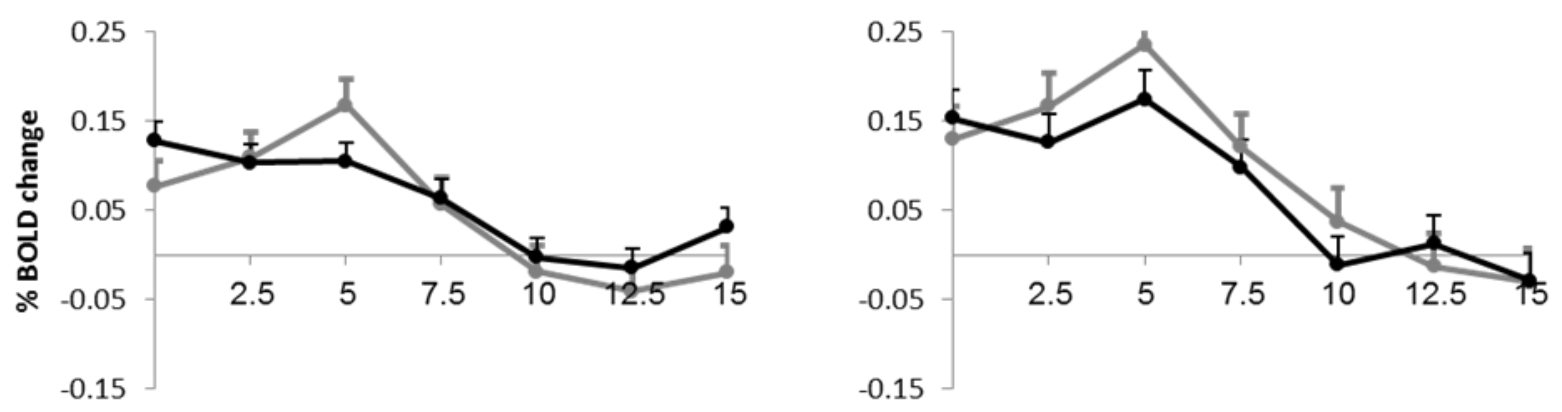

B

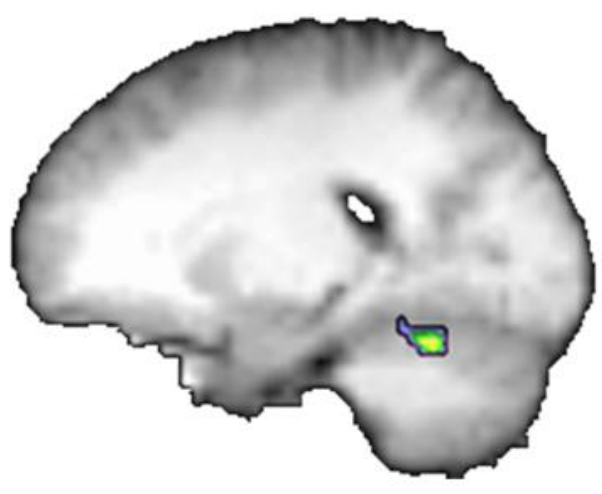

$X=19$

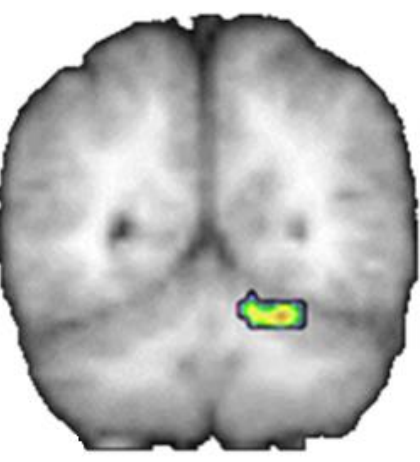

$Y=-57$

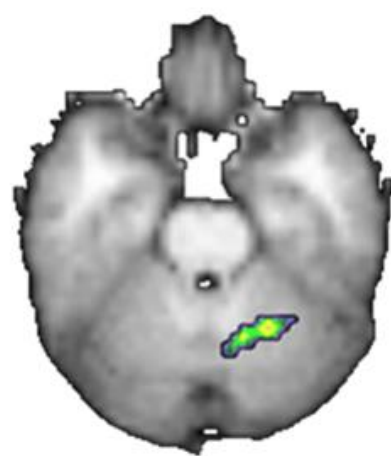

$Z=-24$

Figure 4. sequential dependencies in the right cerebellum, related to mapping stimulus to response. A) Time courses in young adults showed greater activation for switch trials (e.g., incongruent after congruent, congruent after incongruent), while old adults did not. B) Right cerebellar activation from the Previous congruency* Present congruency*Age*Time image is shown in sagittal, coronal and axial slices. Slices are identified by their Talairach coordinates.

\section{Discussion}

We investigated the neural underpinnings of aging effects in the Simon task by comparing BOLD response evoked by congruent, incongruent and neutral targets in a 
group of young and old participants. We found that a broad range of regions, belonging to attentional, control and visual-motor networks showed BOLD responses, which differed in old and young participants. In order to reveal which of these networks may be responsible for the performance difference between young and old, we focused on the neural correlates of sequential effects.

Behaviorally, old adults show greater congruency effects than young adults, mainly because reaction times are disproportionally slowed in incongruent trials. This increased interference of target location on response latencies reflects the fact that sequential effects are diminished in older adults: whereas young adults show diminished interference following an incongruent trial, older adults do not adjust their performance on the basis of the congruency of the previous trial, and have congruency effects that are as large following congruent and incongruent trials (Aisenberg et al., 2014). The finding that age related differences in sequential effects can be diminished with increasing the ITI (Aisenberg et al., 2014), suggests that preparatory processes that take place during the ITI are affected by aging. Because these preparatory processes take place following the previous trial, they are unlikely to be reactive, but rather reflect a proactive mode of control (Braver 2012).

In general, BOLD responses were delayed in older compared to young adults. Moreover, the amplitude of the BOLD response in old adults was diminished, replicating previous findings (e.g. Aizenstein et al., 2004). Because hemodynamic factors are probably also at play, age related differences in the effect of target congruency, observed in a number of regions, are of limited interpretability. As shown in Figure 3, the congruency of the target affected the depth of late components of the BOLD response in both task positive and task negative regions of young participants. In the same regions, older adults show smaller effects of target congruency. This result is not unprecedented, as the depth of BOLD deactivations in task negative regions has been previously found to be sensitive to task difficulty in young, but not old participants (Persson, Lustig, Nelson, \& Reuter-Lorenz, 2007). The timing of these age-related differences in the BOLD response may suggest that they reflect the suppression of task irrelevant processes during the ITI in young, but not old participants.

\section{$\underline{4.1 \text { Lack of congruency effects in control related regions. }}$}

The right anterior Insular cortex was the only region of the cognitive control/saliency networks (Dosenbach et al., 2007; Menon \& Uddin, 2010), where congruency related BOLD signals were affected by the participants' age, suggesting that at least elements 
of this network may contribute to processes engaged by target congruency. In the voxel wise analysis, we did not find significant target congruency by time effects (data not shown) or target congruency by age by time effects in the ACC. Moreover, regional analysis did not reveal the presence of a significant congruency effect in an ACC region defined from the age by time interaction image. While previous studies using the Stroop, Flanker, and Simon tasks, reported congruency effect in the ACC (e.g., Fan et al., 2003; Jonides et al., 2002; Peterson et al., 2002), the exact location within the ACC varied with task. Moreover, not all studies found significant congruency effect in ACC (Egner and Hirsch 2005; Wittfoth et al., 2006). On the other hand, congruency effects have been found outside the control network, mainly in visual and motor regions (Nachev, Wydell, O’Neill, Husain, \& Kennard, 2007; Wittfoth et al., 2006). It has been suggested previously (e.g., Fan et al., 2003; Kornblum et al., 1990) that different tasks give rise to distinct types of conflict, and therefore engage separate neural networks.

\section{$\underline{4.2 \text { Stimulus-response remapping impairment }}$}

Age differences in sequential dependencies were found in the right anterior cerebellum, a region presumably related to learning and storage of new sensori-motor transformations (Imamizu, Kuroda, Yoshioka \& Kawato, 2004). While young adults showed greater activation in this region in switch trials, that is, when the present and previous target congruency differed, old adults showed greater activation following congruent targets, regardless of the preceding target congruency. One interpretation of this finding is that in young adults, processes are recruited following each target, which change stimulus-response contingencies, while in older adults this trial to trial updating is impaired. In older adults, this leads to congruency effects that do not change with trial history, both behaviorally and neurologically. If this idea is correct, then the updating of the relation between target location and response in the Simon task may be akin to stimulus response remapping instructed during task switching. Bischoff-Grethe, Ivry, and Grafton (2002) assessed the effect of attentional switching and stimulus-response remapping on the BOLD signal. Right anterior cerebellum activations were associated with response reassignment. The authors concluded that cerebellar activations reflect the updating of stimulus-response associations. Engagement of the cerebellum during stimulus-response reassignment has been confirmed by later studies (Berger et al., 2005). Children who had undergone resections for cerebellar tumours, showed diminished detection accuracy following a cue instructing a change in the task relevant dimension, supporting the involvement of 
the cerebellum in updating the stimulus response mapping. Interestingly, this impairment was only evident when the cue-target interval was less than $2.5 \mathrm{~s}$, suggesting that the cerebellar lesion specifically impaired the ability to rapidly complete the updating (Courchesne et al., 1994). Our proposal that age related changes in cerebellar activation leads to slowed updating of stimulus response mapping, and thus, loss of sequential effects in the Simon task, is also in keeping with the conclusion that impaired motor and cognitive performance may reflect diminished cerebellar function in older adults (Bernard \& Seidler, 2014), and the observation that the anterior lobe of the cerebellum is particularly vulnerable to aging (Andersen, Gundersen \& Pakkenberg, 2003). Additional evidence supports cerebellum involvement in executive functions tasks (Schweizer, Alexander, Cusimano \& Stuss, 2007; Schweizer, Oriet, Meiran, Alexander, Cusimano \& Stuss, 2007), and its correlation with the pre-frontal cortex (Rammani, 2006).

One methodological issue, which somewhat limits the interpretation of our finding is that they may reflect time on task effects. That is, older adults showed loss of sequential effects, both in behavioral response times, and neural response amplitudes. Given the correlational nature of functional imaging, we cannot conclusively attribute changes in reaction times to changes in neural responses, rather than the other way around. Yet, old adults showed larger BOLD response to congruent than incongruent targets (see figure 4) suggesting that time on task effects were not paramount in shaping the BOLD response in the right cerebellum, at least in older participants. Lesion studies may provide additional evidence to test our hypothesis that slowed stimulus response updating in the cerebellum may account for age related loss of sequential effects in the Simon task (Sheth et al, 2012).

In conclusion, we suggest that aging may interfere with the trial by trial updating of stimulus-response mapping. This process involves the cerebellum, takes place during the inter-trial interval, suggesting that it involves proactive preparatory processes (Braver, 2012) and underlays sequential effects in a Simon task. 


\section{References}

Abrahamse, E. L., \& Van der Lubbe, R. H. (2008). Endogenous orienting modulates the Simon effect: critical factors in experimental design. Psychological research, 72(3), 261-272.

Aisenberg, D., Cohen, N., Pick, H., Tressman, I., Rappaport, M., Shenberg, T., \& Henik, A. (2015). Social priming improves cognitive control in elderly adultsEvidence from the Simon task. PloS one, 10(1), e0117151.

Aisenberg, D., Sapir, A., d'Avossa, G., \& Henik, A. (2014). Long trial durations normalise the interference effect and sequential updating during healthy aging. Acta Psychologica, 153, 169-178.

Aisenberg, D., \& Henik, A. (2012). Stop being neutral: Simon takes control! Quarterly Journal of Experimental Psychology, 65, 295-304.

Aizenstein, H. J., Clark, K. A., Butters, M. A., Cochran, J., Stenger, V. A., Meltzer, C. C., ... \& Carter, C. S. (2004). The BOLD hemodynamic response in healthy aging. Journal of Cognitive Neuroscience, 16, 786-793.

Andersen, B. B., Gundersen, H. J. G., \& Pakkenberg, B. (2003). Aging of the human cerebellum: a stereological study. Journal of Comparative Neurology, 466(3), 356365

Arcaro, M. J., McMains, S. A., Singer, B. D., \& Kastner, S. (2009). Retinotopic organization of human ventral visual cortex. Journal of neuroscience, 29(34), 1063810652.

Atchley, P., \& Kramer, A.F. (1998). Spatial cueing in a stereoscopic display: Attention remains "depth-aware" with age. Journal of Gerontology: Psychological Sciences, 53, 318-323.

Banich, M., Milham, M., Atchley, R., Cohen, N., Webb, A., Wszalek, T., ... \& Magin, R. (2000). fMRI studies of Stroop tasks reveal unique roles of anterior and posterior brain systems in attentional selection. Journal of Cognitive Neuroscience, 12(6), 9881000.

Berger, A., Sadeh, M., Tzur, G., Shuper, A., Kornreich, L., Inbar, D., ... \& Kessler, Y. (2005). Task switching after cerebellar damage. Neuropsychology,19(3), 362.

Bernard, J. A., \& Seidler, R. D. (2014). Moving forward: age effects on the cerebellum underlie cognitive and motor declines. Neuroscience \& Biobehavioral Reviews, 42, 193-207. 
Bialystok, E., Craik, F. I. M., Klein, R., \& Viswanathan, M. (2004). Bilingualism, aging, and cognitive control: Evidence from the Simon task. Psychology and Aging, 19, 290-303.

Bischoff-Grethe, A., Ivry, R. B., \& Grafton, S. T. (2002). Cerebellar involvement in response reassignment rather than attention. The Journal of neuroscience, 22(2), 546553.

Botvinick, M., Braver, T. S., Barch, D. M., Carter, C. S., \& Cohen, J. D. (2001). Conflict monitoring and cognitive control. Psychological Review, 108, 624-652.

Botvinick, M. M., Cohen, J. D., \& Carter, C. S. (2004). Conflict monitoring and anterior cingulate cortex: an update. Trends in cognitive sciences, 8(12), 539-546.

Botvinick, M., Nystrom, L. E., Fissell, K., Carter, C. S., \& Cohen, J. D. (1999). Conflict monitoring versus selection-for-action in anterior cingulate cortex. Nature, $402,179-181$.

Buckner, R. L. (1998). Event-related fMRI and the hemodynamic response. Human Brain Mapping, 6, 373-377.

Buckner, R. L., Snyder, A. Z., Sanders, A. L., Raichle, M. E., \& Morris, J. C. (2000). Functional brain imaging of young, nondemented, and demented older adults. Journal of Cognitive Neuroscience, 12, 24-34.

Braver, T. S. (2012). The variable nature of cognitive control: a dual mechanisms framework. Trends in cognitive sciences, 16(2), 106-113.

Carter, C., Macdonald, A. M., Botvinick, M., Ross, L. L., Stenger, V.A., Noll, D., \& Cohen, J. D. (2000). Parsing executive processes: strategic vs. evaluative functions of the anterior cingulate cortex. Proceedings of the National Academy of Sciences, 97, 1944-1948.

Cashdollar, N., Fukuda, K., Bocklage, A., Aurtenetxe, S., Vogel, E. K., \& Gazzaley, A. (2013). Prolonged disengagement from attentional capture in normal aging. Psychology and Aging, 28, 77-86.

Castel, A. D., Chasteen, A. L., Scialfa, C. T., \& Pratt, J. (2003). Adult age differences in the time course of inhibition of return. Journal of Gerontology: Psychological Sciences, 58B, 256-259.

Cerella, J. (1985). Information processing rates in the elderly. Psychological Bulletin, 98, 67-83.

Courchesne, E., Townsend, J., Akshoomoff, N. A., Saitoh, O., Yeung-Courchesne, R., Lincoln, A. J., ... \& Lau, L. (1994). Impairment in shifting attention in autistic and cerebellar patients. Behavioral neuroscience, 108(5), 848 
Craik, F. I., Morris, L. W., Morris, R. G., \& Loewen, E. R. (1990). Relations between source amnesia and frontal lobe functioning in older adults. Psychology and Aging, 5, 148-151.

Craik, F. I., \& Salthouse, T. A. (Eds.). (2011). The handbook of aging and cognition. Psychology Press.

Craft, J. L., \& Simon, J. R. (1970). Processing symbolic information from a visual display: Interference from an irrelevant directional cue. Journal of Experimental Psychology, 83, 415-420.

Daigneault, S., \& Braun, C. M. (1993). Working memory and the self-ordered pointing task: Further evidence of early prefrontal decline in normal aging. Journal of Clinical and Experimental Neuropsychology, 15, 881-895.

Dale, A. M., \& Buckner, R. L. (1997). Selective averaging of rapidly presented individual trials using fMRI. Human Brain Mapping, 5, 329-340.

De Jong, R., Berendsen, E., \& Cools, R. (1999). Goal neglect and inhibitory limitations: Dissociable causes of interference effects in conflict situations. Acta Psychologica, 101, 379-394.

D’Esposito, M., Zarahn, E., Aguirre, G. K., \& Rypma, B. (1999). The effect of normal aging on the coupling of neural activity to the bold hemodynamic response. Neuroimage, 10, 6-14.

Dosenbach, N. U., Visscher, K. M., Palmer, E. D., Miezin, F. M., Wenger, K. K., Kang, H. C., ... \& Petersen, S. E. (2006). A core system for the implementation of task sets. Neuron, 50(5), 799-812.

Dosenbach, N. U., Fair, D. A., Miezin, F. M., Cohen, A. L., Wenger, K. K., Dosenbach, R. A., ... \& Schlaggar, B. L. (2007). Distinct brain networks for adaptive and stable task control in humans. Proceedings of the National Academy of Sciences, 104(26), 11073-11078.

Duchek, J. M., Hunt, L., Ball, K., Buckles, V., \& Morris, J. C. (1998). Attention and driving performance in Alzheimer's disease. The Journals of Gerontology Series B: Psychological Sciences and Social Sciences, 53, P130-P141.

Duthoo, W., Abrahamse, E. L., Braem, S., Boehler, C. N., \& Notebaert, W. (2014). The heterogeneous world of congruency sequence effects: an update. Frontiers in Psychology, 5.

Egner, T. (2007). Congruency sequence effects and cognitive control. Cognitive, Affective, \& Behavioral Neuroscience, 7(4), 380-390. 
Egner, T., \& Hirsch, J. (2005). Cognitive control mechanisms resolve conflict through cortical amplification of task-relevant information. Nature neuroscience, 8(12), 17841790.

Fan, J., Flombaum, J. I., McCandliss, B. D., Thomas, K. M., \& Posner, M. I. (2003). Cognitive and brain consequences of conflict. NeuroImage, 18, 42-57.

Folstein, M. F., Folstein, S. E., \& McHugh, P. R. (1975). "Mini-Mental State”. A practical method for grading the cognitive state of patients for the clinician. Journal of Psychiatric Research, 12, 189-198.

Forman S. D., Cohen J. D., Fitzgerald M., Eddy W. F., Mintun M. A., \& Noll D. C. (1995). Improved assessment of significant activation in functional magnetic resonance imaging (fMRI): Use of a cluster-size threshold. Magnetic Resonance in Medicine, 33, 636-647.

Friedrich, F. J., Egly, R., Rafal, R. D., \& Beck, D. (1998). Spatial attention deficits in humans: a comparison of superior parietal and temporal-parietal junction lesions. Neuropsychology, 12(2), 193.

Friston, K. J., Holmes, A. P., Worsley, K. J., Poline, J. P., Frith, C. D., \& Frackowiak, R. S. (1994). Statistical parametric maps in functional imaging: a general linear approach. Human brain mapping, 2, 189-210.

Gratton, G., Coles, M. G. H., \& Donchin, E. (1992). Optimizing the use of information: Strategic control of activation and responses. Journal of Experimental Psychology: General, 4, 480-506.

Greenwood, P. M., Parasuraman, R., \& Haxby, J. V. (1993). Changes in visuospatial attention over the adult lifespan. Neuropsychologia, 31, 471-85.

Grefkes, C., \& Fink, G. R. (2005). REVIEW: The functional organization of the intraparietal sulcus in humans and monkeys. Journal of anatomy, 207(1), 3-17.

Hasher, L., \& Zacks, R. T. (1988). Working memory, comprehension, and aging: A review and a new view. In G. H. Bower (Ed.), The psychology of learning and motivation, Vol. 22 (pp. 193-225). New York: Academic Press.

Hommel, B. (1993). The relationship between stimulus processing and response selection in the Simon task: Evidence for a temporal overlap. Psychological Research, 55(4), 280-290.

Hommel, B. (2011). Attention and spatial stimulus coding in the Simon task: a rejoinder to van der Lubbe and Abrahamse (2010). Acta psychologica,136(2), 265268. 
Hommel, B., Müsseler, J., Aschersleben, G., \& Prinz, W. (2001). Codes and their vicissitudes. Behavioral and brain sciences, 24(05), 910-926.

Hommel, B., Proctor, R. W., \& Vu, K.-P. L. (2004). A feature- integration account of sequential effects in the Simon task. Psychological Research, 68, 1-17.

Huettel, S.A., Singerman, J.D., \& McCarthy, G. (2001). The effects of aging upon the hemodynamic response measured by functional MRI. Neuroimage, 13, 161-175.

Imamizu, H., Kuroda, T., Yoshioka, T., \& Kawato, M. (2004). Functional magnetic resonance imaging examination of two modular architectures for switching multiple internal models. Journal of Neuroscience, 24(5), 1173-1181.

Jonides, J., Badre, D., Curtis, C., Thompson-Schill, S. L., \& Smith, E. E. (2002). Mechanisms of conflict resolution in prefrontal cortex. Principles of frontal lobe function, 233-245.

Kerns, J. G. (2006). Anterior cingulate and prefrontal cortex activity in an FMRI study of trial-to-trial adjustments on the Simon task. Neuroimage, 33(1), 399-405.

Kerns, J. G., Cohen, J. D., MacDonald, A. W., Cho, R. Y., Stenger, V. A., \& Carter, C. S. (2004). Anterior cingulate conflict monitoring and adjustments in control. Science, 303(5660), 1023-1026.

Kornblum, S., Hasbroucq, T., \& Osman, A. (1990). Dimensional overlap: cognitive basis for stimulus-response compatibility--a model and taxonomy. Psychological Review, 97(2), 253-270.

Lincourt, A. E., Folk, C. L., \& Hoyer, W. J. (1997). Effects of aging on voluntary and involuntary shifts of attention. Aging, Neuropsychology, and Cognition, 4, 290-303.

Liu, X., Banich, M. T., Jacobson, B. L., \& Tanabe, J. L. (2006). Functional dissociation of attentional selection within PFC: Response and non-response related aspects of attentional selection as ascertained by fMRI. Cerebral Cortex, 16, 827-834. Lu, C. H., \& Proctor, R. W. (1995). The influence of irrelevant location information on performance: A review of the Simon and spatial Stroop effects. Psychonomic bulletin \& review, 2, 174-207.

MacDonald, A. W., Cohen, J. D., Stenger, V. A., \& Carter, C. S. (2000). Dissociating the role of the dorsolateral prefrontal and anterior cingulate cortex in cognitive control. Science, 288(5472), 1835-1838.

Mayr, U., Awh, E., \& Laurey, P. (2003). Conflict adaptation effects in the absence of executive control. Nature Neuroscience, 6, 450-452.

McAvoy, M. P., Ollinger, J. M., \& Buckner, R. L. (2001). Cluster size thresholds for assessment of significant activation in fMRI. Neuroimage, 13(6), 198. 
Meiran, N., Gotler, A., \& Perlman, A. (2001). Old age is associated with a pattern of relatively intact and relatively impaired task-set switching abilities. The Journals of Gerontology Series B: Psychological Sciences and Social Sciences, 56, P88-P102.

Menon, V., \& Uddin, L. Q. (2010). Saliency, switching, attention and control: a network model of insula function. Brain Structure and Function, 214(5-6), 655-667.

Miezin, F. M., Maccotta, L., Ollinger, J. M., Petersen, S. E., \& Buckner, R. L. (2000). Characterizing the hemodynamic response: effects of presentation rate, sampling procedure, and the possibility of ordering brain activity based on relative timing. Neuroimage, 11, 735-759.

Mintun MA, Fox PT, Raichle ME (1989) A highly accurate method of localizing regions of neuronal activation in the human brain with positron emission tomography. Journal of Cerebral Blood Flow Metabolism, 9: 96-103.

Moran, J. M., Jolly, E., \& Mitchell, J. P. (2012). Social-cognitive deficits in normal aging. The Journal of Neuroscience, 32(16), 5553-5561.

Myerson, J., Hale, S., Wagstaff, D., Poon, L. ～W., \& \&mith, G. A. (1990). The information loss model: A mathematical theory of age-related cognitive slowing. Psychological Review, 97, 475-487.

Nachev, P., Wydell, H., O’Neill, K., Husain, M., \& Kennard, C. (2007). The role of the pre-supplementary motor area in the control of action. Neuroimage, 36, 155-163.

Nicoletti, R., \& Umiltá, C. (1989). Splitting visual space with attention. Journal of Experimental Psychology: Human Perception and Performance, 15(1), 164.

Nissen, M.J., \& Corkin, S. (1985). Effectiveness of attentional cueing in older and younger adults. Journal of Gerontology, 40, 185-91.

Ojemann, J. G., Akbudak, E., Snyder, A. Z., McKinstry, R. C., Raichle, M. E., \& Conturo, T. E. (1997). Anatomic localization and quantitative analysis of gradient refocused echo-planar fMRI susceptibility artifacts. Neuroimage, 6, 156-167.

Ollinger, J. M., Shulman, G. L., \& Corbetta, M. (2001). Separating processes within a trial in event-related functional MRI: I. The method. Neuroimage, 13(1), 210-217.

Park, D. C., Polk, T. A., Park, R., Minear, M., Savage, A., \& Smith, M. R. (2004). Aging reduces neural specialization in ventral visual cortex. Proceedings of the National Academy of Sciences of the United States of America, 101(35), 1309113095.

Persson, J., Lustig, C., Nelson, J. K., \& Reuter-Lorenz, P. A. (2007). Age differences in deactivation: a link to cognitive control? Journal of Cognitive Neuroscience, 19(6), 1021-1032. 
Peterson, B. S., Kane, M. J., Alexander, G. M., Lacadie, C., Skudlarski, P., Leung, H. C., ... Gore, J. C. (2002). An event-related functional MRI study comparing interference effects in the Simon and Stroop tasks. Cognitive Brain Research, 13, 427-440.

Proctor, R. W., \& Lu, C.-H. (1994). Referential coding and attention-shifting accounts of the Simon effect. Psychological Research, 56, 185-195.

Ramnani, N. (2006). The primate cortico-cerebellar system: anatomy and function. Nature reviews. Neuroscience, 7(7), 511.

Robinson, D.L., \& Kertzman, C. (1990). Visuospatial attention: effects of age, gender, and spatial references. Neuropsychologia, 28, 291-301.

Salthouse, T. A. (1990). Working memory as a processing resource in cognitive aging. Developmental Review, 10, 101-124.

Salthouse, T. A. (1996). The processing-speed theory of adult age differences in cognition. Psychological review, 103, 403.

Salthouse, T. A. (2016). Theoretical perspectives on cognitive aging. Psychology Press.

Sapir, A., Soroker, N., Berger, A., \& Henik, A. (1999). Inhibition of return in spatial attention: Direct evidence for collicular generation. Nature neuroscience, 2, 1053 1054.

Schweizer, T. A., Alexander, M. P., Cusimano, M., \& Stuss, D. T. (2007). Fast and efficient visuotemporal attention requires the cerebellum. Neuropsychologia, 45(13), 3068-3074.

Schweizer, T. A., Oriet, C., Meiran, N., Alexander, M. P., Cusimano, M., \& Stuss, D. T. (2007). The cerebellum mediates conflict resolution. Journal of Cognitive Neuroscience, 19(12), 1974-1982.

Sebastian, A., Baldermann, C., Feige, B., Katzev, M., Scheller, E., Hellwig, B., ... \& Klöppel, S. (2013). Differential effects of age on subcomponents of response inhibition. Neurobiology of aging, 34, 2183-2193.

Seeley, W. W., Menon, V., Schatzberg, A. F., Keller, J., Glover, G. H., Kenna, H., ... \& Greicius, M. D. (2007). Dissociable intrinsic connectivity networks for salience processing and executive control. Journal of Neuroscience, 27(9), 2349-2356.

Sheth, S. A., Mian, M. K., Patel, S. R., Asaad, W. F., Williams, Z. M., Dougherty, D. D., ... \& Eskandar, E. N. (2012). Human dorsal anterior cingulate cortex neurons mediate ongoing behavioural adaptation. Nature, 488(7410), 218-221. 
Simon, J. R., \& Small, A. M., Jr. (1969). Processing auditory information: Interference from an irrelevant cue. Journal of Applied Psychology, 53, 433-435.

Spieler, D. H., Balota, D. A., \& Faust, M. E. (1996). Stroop performance in healthy younger and older adults and in individuals with dementia of the Alzheimer's type. Journal of Experimental Psychology: Human Perception and Performance, 22, 461-479.

Snyder, A. Z. (1996). Difference image versus ratio image error function forms in PET-PET realignment. Quantification of brain function using PET, 131-137.

Stürmer, B., Leuthold, H., Soetens, E., Schröter, H., \& Sommer, W. (2002). Control over location-based response activation in the Simon task: behavioral and electrophysiological evidence. Journal of Experimental Psychology: Human Perception and Performance, 28(6), 1345.

Talairach, J., \& Tournoux, P. (1988). Co-planar stereotaxic atlas of the human brain. 3-Dimensional proportional system: an approach to cerebral imaging.

Tales, A., Muir, J. L., Bayer, A., \& Snowden, R. J. (2002). Spatial shifts in visual attention in normal ageing and dementia of the Alzheimer type. Neuropsychologia, 40, 2000-2012.

Umilta, C., \& Nicoletti, R. (1985). Attention and coding effects in S-R compatibility due to irrelevant spatial cues. In M. I. Posner \& O. S. M. Martin (Eds.), Attention and Performance XI (pp. 456-471). Hillsdale, NJ: Erlbaum.

Umiltà, C., Rubichi, S., \& Nicoletti, R. (1999). Facilitation and interference components in the Simon effect. Archives Italiennes de Biologie, 137, 139-149.

Van der Lubbe, R. H., \& Abrahamse, E. L. (2011). The premotor theory of attention and the Simon effect. Acta Psychologica, 136(2), 259-264.

Van der Lubbe, R. H., Abrahamse, E. L., \& De Kleine, E. (2012). The premotor theory of attention as an account for the Simon effect. Acta psychologica, 140(1), 2534.

Van der Lubbe, R. H. J., \& Verleger, R. (2002). Aging and the Simon Task. Psychophysiology, 39, 100-110.

Voss, M. W., Erickson, K. I., Chaddock, L., Prakash, R. S., Colcombe, S. J., Morris, K. S., ... \& Kramer, A. F. (2008). Dedifferentiation in the visual cortex: an fMRI investigation of individual differences in older adults. Brain research, 1244, 121-131. Wang, L., \& Weekes, B. (2014). Neural correlates of the Simon effect modulated by practice with spatial mapping. Neuropsychologia, 63, 72-84. 
West, R., \& Bell, M. A. (1997). Stroop color-word interference and electroencephalogram activation: Evidence for age-related decline of the anterior attention system. Neuropsychology, 11, 421-427.

Wittfoth, M., Buck, D., Fahle, M., \& Herrmann, M. (2006). Comparison of two Simon tasks: neuronal correlates of conflict resolution based on coherent motion perception. Neuroimage, 32, 921-929.

Wühr, P., \& Ansorge, U. (2005). Exploring trial-by-trial modulations of the Simon effect. Quarterly Journal of Experimental Psychology, 58A, 705-731.

Yamaguchi, S., Tsuchiya, H., \& Kobayashi, S. (1995). Electrophysiologic correlates of age effects on visuospatial attention shift. Cognitive Brain Research, 3, 41-49.

Zacks, R. T., Radvansky, G., \& Hasher, L. (1996). Studies of directed forgetting in older adults. Journal of Experimental Psychology: Learning, Memory, and Cognition, 22, 143-156. 
Acknowledgements

This work was supported by the Walsh Institute of Cognitive Neuroscience (UKWICN) internal grant (WBI027) and by the British Academy (UK- BA) Small Research Grant (SG100635). 
Supplementary materials:

\begin{tabular}{|c|c|c|c|c|}
\hline Brain region/Coordinates & $\mathbf{X}$ & $\mathbf{Y}$ & $\mathbf{Z}$ & Z score \\
\hline L ParaHippocampal Gyrus & -18 & -60 & -5 & 5.30 \\
\hline R medial ParaHippocampal Gyrus & 3 & -55 & 2 & 5.0 \\
\hline R Striate Cortex & 9 & -79 & 0 & 4.84 \\
\hline L Anterior Temporal & -43 & -36 & 18 & 4.84 \\
\hline L Caudate & -8 & 3 & 10 & 4.80 \\
\hline L Striate Cortex & -5 & -85 & -10 & 4.65 \\
\hline R Posterior Insula & 36 & -26 & 18 & 4.62 \\
\hline R ParaHippocampal Gyrus & 21 & -59 & -2 & 4.43 \\
\hline L Cuneus & -17 & -79 & 17 & 4.21 \\
\hline R Anterior Striate Cortex & 15 & -68 & 4 & 4.19 \\
\hline L Fusiform Gyrus & -26 & -39 & -17 & 4.17 \\
\hline L Superior Parietal Lobule & -13 & -46 & 52 & 4.16 \\
\hline L Collateral Sulcus & -39 & -49 & -19 & 4.16 \\
\hline L Superior Temporal Sulcus & -48 & -35 & 2 & 4.10 \\
\hline L mid Cingulate Gyrus & -8 & -42 & 29 & 4.07 \\
\hline R SMA & 1 & 12 & 59 & 4.02 \\
\hline R posterior Cingulate Gyrus & 6 & -43 & 27 & 4.01 \\
\hline L Fusiform Gyrus & -31 & -60 & -14 & 4.0 \\
\hline R Fusiform Gyrus & 30 & -65 & -10 & 4.0 \\
\hline R Inferior Temporal Gyrus & 38 & -54 & -16 & 3.98 \\
\hline R superior Occipital Gyrus & 13 & -75 & 18 & 3.98 \\
\hline $\mathrm{LACC}$ & -1 & 17 & 39 & 3.96 \\
\hline R Precuneus & 16 & -72 & 30 & 3.96 \\
\hline L Precuneus & -10 & -59 & 47 & 3.95 \\
\hline L Transverse Temporal Gyrus & -51 & -26 & 12 & 3.94 \\
\hline $\mathrm{R}$ anterior ParaHippocampal Gyrus & 16 & -39 & -6 & 3.94 \\
\hline $\mathrm{R}$ midbrain & 10 & -29 & -7 & 3.89 \\
\hline L Occipital Gyrus & -19 & -81 & -15 & 3.84 \\
\hline L MT+ & -45 & -69 & -2 & 3.82 \\
\hline R Precuneus & 3 & -50 & 49 & 3.81 \\
\hline R superior Temporal Sulcus & 61 & -27 & 20 & 3.79 \\
\hline
\end{tabular}




\begin{tabular}{|c|c|c|c|c|}
\hline L Occipital Gyrus & -8 & -94 & -13 & 3.79 \\
\hline L Medial Intra-Parietal Sulcus & -24 & -63 & 45 & 3.76 \\
\hline L Precuneus & -4 & -68 & 47 & 3.75 \\
\hline L Posterior Insula & -34 & -26 & 17 & 3.74 \\
\hline L SMA & -7 & 7 & 57 & 3.73 \\
\hline R Lingual Gyrus & 26 & -44 & -7 & 3.65 \\
\hline R Inferior Frontal Gyrus & 44 & 12 & 31 & 3.59 \\
\hline R Lingual Gyrus & -45 & -58 & -11 & 3.58 \\
\hline L Hippocampus & -34 & -25 & 2 & 3.57 \\
\hline R Superior Temporal Gyrus & 48 & -25 & 9 & 3.56 \\
\hline R Temporo-Parietal Junction & 42 & -53 & 23 & 3.50 \\
\hline L Lateral Geniculate Nucleus & -23 & -32 & -5 & 3.48 \\
\hline L Precuneus & -14 & -80 & 28 & 3.47 \\
\hline R Red Nucleus & 13 & -19 & -7 & 3.46 \\
\hline L MFG & -42 & 10 & 28 & 3.44 \\
\hline L pos occ & 24 & -99 & -8 & 3.43 \\
\hline $\mathrm{R}$ lat TPJ & 54 & -56 & 21 & 3.43 \\
\hline L Striate Cortex & -9 & -85 & 18 & 3.42 \\
\hline L Inferior Frontal Gyrus & -52 & 10 & 31 & 3.40 \\
\hline L Superior Temporal Sulcus & 56 & -23 & 4 & 3.37 \\
\hline R RetroSplenial Cortex & 8 & -52 & 22 & 3.36 \\
\hline R Cerebellum & 3 & -58 & -40 & 3.32 \\
\hline R Thalamus & 13 & -22 & 4 & 3.30 \\
\hline R Mid Cingulate Gyrus & 7 & -26. & 31 & 3.25 \\
\hline L Striate Cortex & -1 & -85 & -18 & 3.24 \\
\hline R Occipital Gyrus & 19 & -78 & -11 & 3.24 \\
\hline R Transverse Temporal Gyrus & 44 & -31 & 16 & 3.22 \\
\hline L inferior Central Sulcus & 42 & -15 & 45 & 3.21 \\
\hline L Striate Cortex & 8 & -94 & 2 & 3.20 \\
\hline
\end{tabular}

Table S1 - Talairach Coordinates of the Peaks in the age by time Multiple Comparison Corrected z-transformed Map. 